\title{
GOVERNANÇA EMPRESARIAL, RISCOS E CONTROLES INTERNOS: A EMERGÊNCIA DE UM NOVO MODELO DE CONTROLADORIA
}

\author{
Nilton Cano Martin \\ Professor Doutor do Depto. de Contabilidade e Atuária da FEA-USP \\ cano@plus.com.br \\ Lílian Regina dos Santos \\ Mestranda em Controladoria e Contabilidade da FEA-USP \\ lilian.santos@itau.com.br \\ José Maria Dias Filho \\ Prof. Doutor do Depto. de Ciências Sociais Aplicadas da \\ Universidade Estadual de Feira de Santana - BA \\ Prof. do Programa de Pós-Graduação em Controladoria da Universidade Federal da Bahia \\ E-mail:zemariadias@uol.com.br
}

\section{RESUMO}

O exercício dos poderes de governança dentro de uma empresa depende em alto grau da implantação de um sistema de identificação, avaliação e controle dos riscos que cercam a gestão dos recursos nela investidos. Como os que exercem a governança não têm poder executivo, fatalmente um desses riscos é o de agenciamento, segundo o qual os administradores dos recursos empresariais, ao darem prioridade aos seus próprios interesses, podem não aplicá-los da forma mais adequada aos acionistas/proprietários. A governança deve, pois, cercar a administração dos recursos empresariais com um sistema de controle de gestão. Esse sistema, que deve levar em consideração os riscos que são inerentes aos negócios e compreende o controle da custódia, do desempenho e da qualidade da informação, é, neste artigo, conceituado e descrito em termos das linhas gerais da sua composição e principais instrumentos. Demonstra-se, finalmente, que tais controles devem ser feitos de forma integrada e unificada num único órgão e que esse órgão deve ser a Controladoria, que deve ser reformulada e ter um posicionamento na estrutura organizacional das empresas totalmente independente dos órgãos de administração. Essas são as bases do chamado novo modelo de Controladoria.

Palavras-chave: Governança, Agenciamento, Risco, Controles internos, Controladoria.

\section{ABSTRACT}

Corporate governance highly depends on the installation of a system for the identification, evaluation and control of the risks surrounding the administration of the invested resources. Since Board members do not have executive power, one of the business risks is always the agency risk, according to which business resource managers may put their own interests and priorities ahead of the interests and priorities of the owners/ shareholders. Hence, the Board must surround the administration of business resources with a management control system, considering inherent business risks and encompassing three types of control: custody, performance and information quality. In this article, we show the main concepts and tools of this system and argue that it needs to be integrated and unified in one single organ, which must be the Controller's Office. This function needs to be reformulated so as to obtain a totally independent position in the organizational structure of companies. This is the foundation of the new Controllership model.

Keywords: Governance, Agency theory, Risk, Internal controls, Controllership. 


\section{INTRODUÇÃO}

Nos dias atuais, a governança vem sendo cada vez mais enfaticamente discutida em associação com eventos e transformações empresariais tão díspares como os movimentos de fusão e aquisição de empresas, o elevado custo de capital, a baixíssima profissionalização das companhias dos países emergentes e a necessidade da privatização de empresas estatais. Além disso, a qualidade da governança tem sido o foco em qualquer discussão mais séria sobre as grandes crises empresariais das últimas duas décadas, tais como, internacionalmente, a do Barings e a do grupo editorial Maxwell na Inglaterra, a das empresas de poupanças e empréstimos, a da Enron, a da WorldCom e outras nos E.U.A., a situação préfalimentar de uma série de grandes bancos japoneses, a derrocada de um bom número de chaebols coreanos, bem como, no Brasil, as liquidações dos Bancos Nacional e Econômico e de todo o sistema bancário estatal comercial e de investimentos, além das espetaculares falências do Mappin, da Mesbla, da Encol e da Transbrasil, entre outras. Por que a governança é apontada como a grande falha, o grande pecado original em todos esses colapsos empresariais? Há algo de especialmente falho no governo das empresas no mundo atual? Quem é responsável pelas mazelas da governança nas empresas? O que é, afinal, uma governança corporativa de qualidade? Do que ela depende?

Este artigo busca responder a tais questões com base na experiência internacional recente evidenciada pela literatura, bem como no acompanhamento e na observação direta de oito empresas nacionais de grande porte, que, nos últimos cinco anos, estão buscando a instalação de sistemas mais adequados de governança e gestão'. Entrando numa área ainda pouco explorada pela teoria, o objetivo fundamental do trabalho é demonstrar, numa seqüência lógica: (1) que a governança é necessária numa empresa moderna; (2) que não pode existir governança empresarial sem controles internos; (3) que a eficácia dos controles internos exige que eles sejam unificados e harmonizados entre si e, finalmente, (4) que a Controladoria é o órgão mais adequado para centralizar os controles, desde que ela seja independente da gestão e integre a análise e a avaliação dos riscos empresariais com suas técnicas de contabilização e avaliação de desempenho.

\section{A NATUREZA DA GOVERNANÇA E OS CONTROLES INTERNOS}

Para entender o novo papel e os novos problemas da governança é preciso atentar para duas características do moderno mundo empresarial. A primeira é que a propriedade das empresas, antes concentrada numa única pessoa ou num pequeno grupo, hoje está usualmente bastante dividida e disseminada num grande número de acionistas, que são os que contribuem com o capital social. A segunda é que, diferente do passado em que o dono, o "capitão da empresa", também era o principal executivo, há nas empresas modernas uma clara separação entre os que detêm a propriedade e os que realizam a gestão do capital investido. Por que se deu essa separação?

Porque a administração empresarial, principalmente nas grandes organizações, se tornou um trabalho extremamente complexo, que exige especialistas em diferentes áreas funcionais, tais como produção, comercialização, finanças, desenvolvimento de produtos, recursos humanos, etc. Dessa forma, a separação da propriedade e da gestão é um arranjo institucional que, no mundo moderno, cria imensas oportunidades para o desenvolvimento do patrimônio das empresas, já que a organização é dirigida por indivíduos cujas qualificações são muito maiores do que um único proprietário ou mesmo um pequeno grupo de proprietários jamais poderia alcançar (TEDLOW \& JOHN JR., 1986; RAJAN \& ZINGALES, 2000).

Como uma parte dos novos proprietários/acionistas, os minoritários, não têm qualquer incentivo para exercer diretamente a gestão da empresa dada a sua pequena participação individual no capital social (HART, 1995), e como a outra parte, os majoritários, se afastam dessa gestão direta porque, em geral, Ihes faltam os requisitos necessários, eles delegam essa função a um grupo de executivos, que são, efetivamente, os que tomarão as decisões necessárias para tornar,

\footnotetext{
Setores das empresas: Uma do setor de alimentação, uma de aviação, uma universidade privada, uma construtora, um hospital privado, uma varejista, uma fabricante de bens de capital e uma fundação sem fins lucrativos.
} 
verdadeiramente, produtivo e rentável o capital investido pelos proprietários/acionistas.

Entretanto, se cada decisão de uma empresa tivesse que ser submetida a uma assembléia de acionistas, as empresas, como é óbvio, ficariam paralisadas. É inevitável, portanto, que haja uma transição de poder para as mãos dos administradores, o qual deve ser suficientemente amplo para que possam tomar decisões rapidamente e assumir riscos razoáveis. Mas esse poder não pode ser absoluto, nem totalmente discricionário. A diretriz fundamental é que os recursos empresariais devem sempre ser empregados no interesse dos acionistas/proprietários. É para assegurar que essa diretriz seja cumprida que é criado, na empresa, o Conselho de Administração (board), um órgão exclusivamente constituído para representar os acionistas/proprietários e que tem a obrigação legal de agir como um intermediário entre os investidores participantes da empresa e os gestores da organização (PRATT \& ZECKHAUSER, 1984; JENSEN \& MECKLING, 1999; VIVES, 2000).

O conselho é investido da ascendência e dos poderes de governança sobre os gestores da empresa, os quais, em sua essência, Ihe permitem:

- Orientar sua ação, através da fixação da missão, objetivos e metas da companhia, os quais, consubstanciando as expectativas dos acionistas/proprietários (e dos demais stakeholders), deverão nortear as estratégias e as operações empresariais.

- Fiscalizar se as aplicações que fazem dos recursos da empresa estão em sintonia com os interesses dos acionistas/prioritários, mediante o controle de suas decisões e ações em relação aos propósitos, objetivos e metas fixados.

Assim, um sistema de governança é a fixação pelo Conselho dos mecanismos, estruturas e incentivos, que compõem o sistema de controle de gestão e que devem direcionar o comportamento dos administradores para o cumprimento dos objetivos estipulados pelos acionistas/proprietários e assegurar que deles não se afastem "por má-fé, negligência, cupidez ou simples incompetência" (HELLWIG, 2000).
Entretanto, ainda hoje, na maior parte das empresas, os administradores, que já têm o poder de decidir e fazer, têm, também, paradoxalmente, o poder de informar sobre o que fazem, tanto para o Conselho como para os proprietários/acionistas². Como são eles que aplicam os recursos investidos na empresa e também os que produzem as informações relacionadas sobre suas decisões, podem se formar substanciais assimetrias de informação favorecendo os administradores, entre os quais, infelizmente, estão aqueles que foram acima tipificados por Hellwig. Esse risco, um dos maiores que cercam uma empresa e sua governança, é conhecido como o risco do agenciamento (HARRIS \& TOWNSEND, 1981).

É, pois, da necessidade do equacionamento e da contenção do risco de agenciamento que decorrem as três fundamentais atribuições da governança moderna, todas voltadas ao controle da gestão dos recursos mobilizados pela empresa e que devem ser aplicados para produzir valor para os acionistas/proprietários:

1. Assegurar que todas as obrigações legais e contratuais da empresa sejam atendidas e seus recursos sejam adequadamente conservados e empregados na missão empresarial, sem que ocorram carências de proteção, fraudes, abusos de poder ou desvios dos objetivos. Esse é o chamado problema do controle da custódia dos recursos.

2. Mas, conforme dispõe a parábola bíblica dos dez talentos (MATHEUS 25: 14-30), os recursos mobilizados pela empresa não existem apenas para serem preservados. É preciso assegurar que sejam aplicados de forma a gerar resultados para os acionistas/proprietários e que esses resultados estejam em conformidade com suas expectativas e sua percepção dos riscos do negócio. Esse é o chamado problema do controle do desempenho dos recursos.

3. Por fim, é preciso assegurar que os administradores, que devem informar os acionistas sobre a custódia e o desempenho dos recursos investidos, conforme (1) e (2) acima, e que têm o poder de influenciar diretamente a produção de tais informações (coleta e tratamento dos

\footnotetext{
${ }^{2}$ Na maioria das empresas, o relacionamento de qualquer executivo ou profissional de controle com o conselho somente se dá através do presidente. Para tornar ainda mais
} grave o problema, em algumas empresas o próprio papel do presidente do conselho de administração é exercido pelo presidente executivo. 
dados, bem como o estabelecimento de métodos de mensuração e comunicação dos resultados da empresa), não irão praticar, deliberadamente ou não, a omissão, a ocultação, a distorção ou o atraso da sua comunicação. Esse é o problema do controle da veracidade e da qualidade da informação.

Para estabelecer um sistema de controle da gestão dos recursos, a governança se depara, inevitavelmente, com a necessidade de tratar os riscos empresariais, que são "eventos futuros e incertos que podem influenciar de forma significativa o cumprimento dos objetivos de uma firma" (MCCRIMMON \& WEHRUNG, 1986).

À primeira vista, pode-se ter dos riscos uma visão desfavorável, isto é, entendê-los apenas como a possível ocorrência de eventos que têm impactos prejudiciais sobre os resultados ou sobre o patrimônio da empresa. Essa é a perspectiva do custodiador de recursos, cuja função é, unicamente, a de proteger os ativos da empresa de eventos que levem a perdas, tais como: fogo, inundações, perda de reputação, etc. Entretanto, os riscos são inerentes a todos os negócios e, como se fossem duas faces de uma moeda, é impossível perseguir oportunidades de gerar lucros sem correr riscos. Um projeto de investimento, por exemplo, voltado para expandir os mercados, a produção e os lucros de uma firma está sempre cercado de inúmeros riscos. Possíveis ocorrências de acts of God, tais como inundação, fogo, vendavais, tremores de terra, etc., que podem levar a perdas dos ativos envolvidos no projeto, são alguns desses riscos. Outros, todavia, são ligados à própria natureza do negócio, entre os quais uma possível reação dos concorrentes, tentando impedir ou se antecipar à expansão pretendida com o projeto, o que também acarretaria efeitos negativos sobre os resultados e os retornos previstos. Deveria a empresa implantar o projeto? Sim, mas somente mediante uma garantia razoável de que os riscos e retornos previstos estejam sendo adequadamente identificados e avaliados e demonstrem um balanceamento favorável.

Assim, a tarefa central da governança moderna é implantar ${ }^{3}$ na empresa um conjunto de controles e incentivos para solucionar de forma integrada os problemas da custódia e do desempenho dos recursos nela investidos dentro de um ambiente de riscos, o que significa, inclusive, considerar que "all business risks are also risks of poor management" (JENSEN \& MECKLING, 1999), ou seja, atentar para o risco de agenciamento e evitar que tais controles possam ser infectados pela manipulação deliberada ou incompetente das informações.

Além de colocar em ação os controles mencionados, é sabido que o Conselho tem outros instrumentos de poder para induzir o correto alinhamento dos executivos com os objetivos dos proprietários. A designação e a demissão dos diretores, a fixação de sua remuneração, de suas atribuições, assim como o estabelecimento de incentivos tais como sua participação nos resultados das empresas, por exemplo, são também instrumentos de governança. Não obstante, esses outros mecanismos são apenas complementares e, é claro, só podem ser corretamente aplicados se a arquitetura dos controles internos da gestão for suficientemente abrangente, estiver adequadamente instalada e for eficazmente utilizada. As origens de todas as grandes crises empresariais mencionadas no caput deste trabalho estavam em deficiências de controle, que revelaram as profundas carências de governança das empresas envolvidas e sua total alienação em relação aos riscos que permeavam suas organizações (VIVES, 2000).

Tipologia dos Riscos Empresariais (OLSSON, 2002; YOUNG \& TIPPINS, 2001).

Como foi dito, uma empresa está sujeita a uma grande diversidade de riscos durante a condução de seus negócios e conhecê-los é fundamental, já que aqueles aos quais está exposta e que não sabe reconhecer são os que se revelam mais contundentes.

Os riscos empresariais podem ser classificados em três grandes dimensões ou áreas, cada uma delas com um certo número de grupos de risco incluídos. Alguns desses riscos pertencem a mais do que uma área. Essas três principais classes do risco empresarial, chamadas de riscos funcionais, são discriminadas a seguir. $\mathrm{O}$ esquema da Figura 1 mostra conceitualmente que os controles devem estar obrigatoriamente focalizados sobre eles:

\footnotetext{
${ }^{3} \mathrm{O}$ poder de governo de uma empresa permite que o conselho possa exigir e comandar tal implantação, determinando sua natureza, formas de funcionamento e fluxo de informações, quer diretamente através dos administradores, quer indiretamente através de consultores externos especializados.
} 
- Riscos de propriedade: são associados à mobilização, aquisição, manutenção e disposição dos ativos (com exceção dos ativos humanos). Boa parte desses riscos são focalizados pelo controle de custódia, mas o controle de desempenho e até o de qualidade informativa também se voltam a alguns desses riscos.

- Riscos de processo: são os que se originam do uso ou da operação dos ativos para alcançar os objetivos empresariais. A maioria dos riscos dessa área são focalizados pelo controle de desempenho, mas há alguns que se encontram na órbita da custódia e da informação.

- Riscos comportamentais: são os riscos vinculados à aquisição, manutenção, utilização e disposição dos ativos empresariais de base humana, entre as quais se encontra a capacidade de gestão. Naturalmente, tais riscos se encontram na esfera dos controles de desempenho e da qualidade de informação.

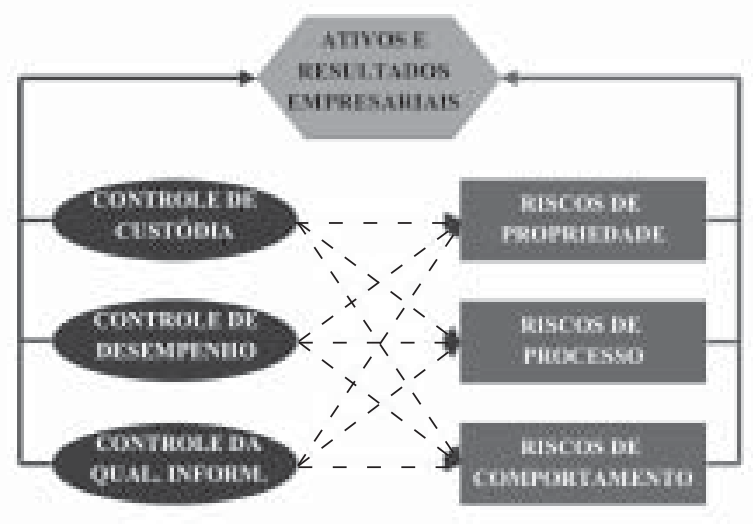

Figura 1: Controles e Riscos

Dentro de cada uma das áreas acima, há os grupos de risco, que são conjuntos de riscos empresariais, alguns dos quais comuns a todas as organizações e outros específicos de determinados setores de atividade. Por exemplo, riscos de fraudes, sabotagem, injúria, processos trabalhistas, preenchimento errôneo de contratos, etc., são mais ou menos comuns a todas as organizações. Alguns, todavia, são específicos ou "naturais" de alguns tipos de negócio. Os riscos advindos de ameaças externas, como, por exemplo, os de mudanças tecnológicas, são bastante diferentes quando se compara os que cercam as atividades bancárias àqueles que estão presentes nas atividades de produção de alimentos, já que são totalmente distintos os fatores ligados a seus produ- tos, mercados, preferências dos seus clientes/usuários, processos internos de trabalho, ritmo de mudança tecnológica, etc.

Para dar um simples exemplo da diferenciação entre os riscos específicos e gerais, considere-se uma companhia de aviação que transporta passageiros entre cidades brasileiras de diferentes Estados. Ela está sujeita aos riscos específicos ou "naturais" de queda de aeronaves, atrasos e impedimento de vôos causados por problemas de manutenção, danos aos equipamentos por causa de fogo, avarias de cargas de terceiros por inadequada armazenagem e movimentação, etc. Entretanto, há outros riscos a que essa empresa está exposta, tais como os riscos de elevação da taxa do dólar ou dos preços do petróleo, que podem não ser tão evidentes por serem sistêmicos ou gerais, mas podem incrementar significativamente os seus custos de operação ou manutenção e ter também um impacto negativo sobre seus resultados.

Discriminando os agrupamentos de risco dentro de cada categoria, se tem, dentro dos riscos de propriedade:

- Riscos de perdas de ativos críticos: Riscos de perdas totais ou parciais de valor de ativos empresariais ou sob sua responsabilidade (dados em garantia como penhor, hipoteca ou alienação fiduciária), que são associadas a eventos destrutivos, tais como: fogo, inundações, terremotos, etc., quer sejam eles originados em causas naturais (acts of God) ou provocados pelo homem. Estão também neste agrupamento os riscos de perdas de intangíveis (conhecimento especializado, experiência, capacidade de liderança, etc.), com a possível saída da empresa das pessoas que o possuíam.

- Riscos estratégicos ou externos: São os que têm origem em forças ambientais que estão fora do controle da organização, mas que podem afetar o valor de ativos específicos ou a própria empresa como um todo. Algumas dessas forças são, por exemplo, demandas de clientes ou fornecedores; alterações nas características dos mercados de insumos (fornecedores de materiais, trabalho, recursos financeiros, etc.) ou de produtos (entrada de novos produtos substitutivos, aumento da intensidade da concorrência através dos preços, etc.); mudanças da regulamentação governamental 
(regras contra a poluição ambiental ou a criação de um novo tributo, por exemplo); tecnologia (surgimento de novas tecnologias de automação industrial, por exemplo), políticas/econômicas (recessão, por exemplo); etc.

- Riscos financeiros: Embora pudessem ser classificados entre os externos, tais riscos, dada a sua importância para as instituições financeiras e para a área financeira das empresas em geral, devem formar um agrupamento específico. São os riscos de mercado (referentes a movimentos desfavoráveis da taxa de juros, das taxas de câmbio ou de qualquer índice de reajuste dos preços de um contrato, bem como os que se referem às dificuldades ou incapacidade de transferir aumentos de custos para o mercado através dos preços), os riscos de crédito (relativos à incapacidade de um devedor de cumprir os termos de seu contrato) e os riscos de liquidez (relativos à impossibilidade de liquidar ativos ou de obter financiamento).

Os riscos de processo incluem os seguintes grupos:

- Riscos de operação humana (alguns são também riscos de propriedade): Riscos de perdas totais ou parciais de recursos que estejam sendo processados, e que são associadas a operações ou controles não apropriados dos ativos e direitos da empresa e que têm causas humanas. Mas essa categoria de riscos é muito ampla, envolvendo também todos os que se originam em processos produtivos e de comercialização defeituosos que podem acarretar problemas de reputação e até demandas judiciais para reparação de perdas e danos. Outros riscos importantes desse grupo são os que são provenientes das deficiências dos processos executivos de planejamento, controle e de tomada de decisão, que, por se originarem no topo estratégico da empresa, podem levá-la a prejuízos extremos. A derrocada do Barings, por exemplo, teve origem em processos de controle mal formulados pela alta administração do Banco.

- Riscos de defeitos dos equipamentos ou dos processos: Riscos que se originam não em imperfeições das atividades humanas, mas de falhas de funcionamento de máquinas e equipamentos, de software, de sistemas ou de processos de trabalho.
- Fraudes e omissões (são também riscos de propriedade e riscos comportamentais): São riscos inerentes aos processos que se originam em deliberadas falsificações, atividades ilegais (ou não recomendáveis eticamente), bem como em distorções de informações feitas por empregados, fornecedores, clientes, administradores, etc., em nome da empresa ou contra ela. Exemplos desses riscos são desvios de dinheiro através de compras falsificadas, recebimento de propinas, esquemas de preços deturpados, participações em concorrências públicas manipuladas, retenção de informações vitais, preparação defeituosa de relatórios, etc.

Os riscos comportamentais têm uma correlação elevada com todos os riscos de propriedade e de processo vistos anteriormente. Eles incluem:

- Riscos de insatisfação ou desmotivação: Riscos ligados à improdutividade resultante da seleção ou da promoção de pessoas sem capacidade, adoção de sistemas de remuneração de baixa qualidade, não-reconhecimento das qualidades de indivíduos com alto potencial, inexistência de suficientes desafios e oportunidades de crescimento, incapacidade de treinamento e desenvolvimento de recursos humanos em áreas relevantes para a competitividade da empresa, etc. Esses riscos, como é lógico, estão estreitamente ligados aos riscos de perdas de intangíveis críticos de base humana e aos riscos dos processos executivos.

- Riscos da disfuncionalidade dos ambientes de trabalho: Riscos aos quais os empregados estão expostos por trabalhar em tal ambiente e os riscos para a organização ao permitir que os empregados estejam sujeitos a tais riscos. Exemplos de tais riscos: assédios sexuais ou outros tipos de violências no ambiente de trabalho, pressão excessiva para chegar aos objetivos, sabotagem ou roubo de empregados, acidentes de trabalho em grande volume, etc.

- Riscos de percepção e julgamento: São os que têm origem em atitudes, percepções e valores que prevalecem em certos grupos influentes internos, como a alta direção e que podem levar a decisões e comportamentos negativos em relação à empresa ou a alguns stakeholders, 
levando-a a incidir em outros riscos. Por exemplo, uma cultura imediatista, de apresentar bons resultados a qualquer custo, como a que havia na Enron, por exemplo, levou-a fraudar demonstratações financeiras para simular um bom desempenho. Um comportamento similar pode, também, levar à fraude de demonstratações financeiras para minimizar a carga tributária.

- Riscos de atitude perante os riscos: São os que resultam de uma demasiada cautela ou de um excesso de temeridade dos administradores, especialmente os da alta direção, em relação ao riscos que cercam a empresa (MARCH \& SHAPIRA, 1987).

\section{CONTROLE DA CUSTÓDIA}

Conhecendo todos os possíveis riscos que cercam uma companhia, o controle de custódia começa por identificar aqueles aos quais seus ativos e atividades estão efetivamente expostos. Esse trabalho, usualmente, é feito por consultores externos especializados ou pelo concurso de executivos das diferentes áreas funcionais de uma empresa (BARTON et al., 2002). Cabe à governança selecionar o método mais confiável. Em geral, como nas empresas brasileiras mencionadas, os dois são utilizados simultaneamente, de forma colaborativa.

Por exemplo: uma grande empresa brasileira do setor de alimentos reuniu os membros do Conselho, da Diretoria Executiva e de uma Consultoria Externa com mais outras 38 pessoas "selecionadas internamente de acordo com o seu grau de visibilidade e conhecimento da empresa, formando um conjunto altamente representativo de todos os mercados, produtos e operações nos quais a empresa está envolvida" (palavras do Presidente do Conselho dessa companhia). Esse grupo identificou a exposição da empresa a 52 tipos de riscos.

Não basta, todavia, conhecer e identificar os ris- cos específicos que cercam uma organização. Para cada tipo de negócio, há riscos mais ou menos importantes e, mesmo para um determinado negócio, a importância dos riscos varia no tempo e lugar. A governança deve, então, conhecer a probabilidade da ocorrência de cada risco e saber o impacto que sua materialização poderá causar nos ativos empresariais e/ou na sua capacidade de produzir resultados. Isto significa avaliar ou medir os riscos (CULP, 2002; GLEASON, 2000).

A avaliação de riscos pode ser feita de forma bastante sofisticada, empregando métricas e métodos estatísticos objetivos, tais como Value-at-Risk (VaR), o Earnings-at-Risk (EaR), o Risk-Metrics e outros (CULP, 2002). Entretanto, para a grande maioria das empresas e para a maior parte dos riscos, as avaliações são, hoje, feitas de forma qualitativa e bastante subjetiva, mesmo quando são utilizados aparatos numéricos, tais como as escalas de Likert ou o método Delphi (MALHOTRA, 1999; CROUHY et al., 2001). Isto não parece descartar sua utilidade para os integrantes dos conselhos. Um membro do board da TRW, por exemplo, foi claro: "É claro que procuramos fazer medidas quantitativas de todos os riscos, mas, no momento, somente estamos tendo sucesso com os riscos financeiros. Em todas as outras categorias de risco não conseguimos desenvolver tais medidas e usamos métodos de avaliação da sua importância baseados em nosso julgamento. Como temos um bom conhecimento de nosso negócio, o fato de não podermos medir com precisão certos riscos não nos preocupa, já que, francamente, achamos que certos riscos jamais poderão ser submetidos a uma mensuração e a uma métrica precisa" (Business Week, 17/02/2003).

Na prática, para a avaliação dos riscos o que primeiro se faz é estimar a freqüência esperada das ocorrências de risco. Por exemplo, a caracterização dos riscos utilizada por uma grande empresa construtora brasileira é a seguinte:

\begin{tabular}{|c|c|c|c|c|c|c|c|c|}
\hline TIPO & 8 & 7 & 6 & 5 & 4 & 3 & 2 & 1 \\
\hline Nome & Contínuo & Muito freqüente & Freqüente & Ocasional & Pouco provável & Improvável & Raro & Remoto \\
\hline Probabilidade & 100/ano & 10/ano & 1/ano & $0,1 /$ ano & $1 \times 10^{-2} / a n o$ & $1 \times 10^{-3} /$ ano & $1 \times 10^{-4}$ /ano & $1 \times 10^{-5} /$ ano \\
\hline
\end{tabular}


O passo seguinte é estimar o possível impacto de um determinado risco empresarial, usualmente medido por graus de gravidade. Tais graus consideram os dois tipos de perdas possíveis para os acionistas/proprietários: (a) impactos sobre a capacidade da empresa de obter os resultados esperados; (b) impactos diretos sobre os recursos mobilizados e aplicados. O grau de gravidade utilizado pela empresa construtora acima citada é o seguinte:

\begin{tabular}{l|c|c|c|}
\hline \multirow{2}{*}{\multicolumn{1}{c|}{ Impacto em: }} & \multicolumn{3}{|c}{ Impactos Estimados } \\
\cline { 2 - 4 } Resultados esperados & $<$ de $\mathbf{3 \%}$ & De $\mathbf{3} \%$ a $\mathbf{1 0} \%$ & $>\mathbf{1 0 \%}$ \\
\hline Ativos empresariais & baixos & moderados & elevados \\
\hline
\end{tabular}

Nessa mesma construtora, como cada risco é avaliado em termos dos seus impactos e probabilidade de ocorrência, são elaborados perfis específicos, conforme o da Figura 2.

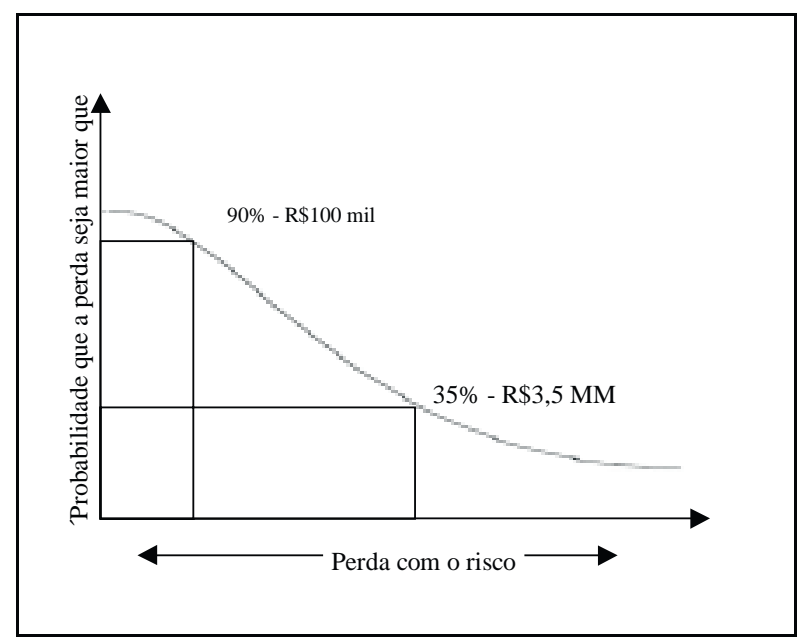

Figura 2: Probabilidade de Perda com um Risco Determinado (Perdas em Recebíveis)

Ainda que possam ter uma probabilidade muito baixa, alguns riscos podem ter repercussões tão severas que sua materialização impediria que a empresa continuasse a funcionar normalmente como uma entidade produtiva. São os riscos extremos. Um dos papéis fundamentais da governança é garantir aos acionistas/proprietários que, mesmo no caso de ocorrência de um evento de impacto extremo, o seu patrimônio estará a salvo (DOHERTY, 2000).

Com o resultado das avaliações, é preparado um mapa geral de controle dos riscos da empresa, como o que é apresentado no Quadro 1 (extraído do Relatório de Administração de 1997 da
Microsoft $)^{4}$. Tal quadro é sumamente importante para que a governança conheça e avalie a totalidade dos riscos que cercam a organização, as probabilidades de sua ocorrência e a gravidade do seu impacto sobre o patrimônio empresarial (se os possíveis sinistros forem suportados internamente). A disposição particular do mapa de riscos existentes numa certa data é chamado de perfil de risco da empresa, naquela data.

O perfil atual de riscos de uma empresa e as estimativas de suas prováveis tendências futuras são os instrumentos básicos usados pela governança para elaborar diretrizes para a administração dos riscos. $O$ perfil de riscos de uma empresa deve ser desagregado por unidades de negócio, áreas funcionais e até por dirigentes do segundo e do terceiro escalão para auxiliar a fixação de responsabilidades pela gestão dos riscos em cada setor.

Em função da avaliação e do mapeamento dos riscos de custódia, cabe ao Conselho, em nome dos acionistas/proprietários, fixar a sua tolerância ou "apetite" aos diferentes tipos de riscos em termos claros e, sempre que possível, de forma quantitativa.

Para cada exposição ao risco identificada e avaliada na empresa é estabelecido um limite máximo de perdas de resultados ou de ativos, assim como as freqüências aceitáveis. O Conselho da firma de aviação acima mencionada, procurando proteger os resultados esperados pelos seus acionistas, pode estabelecer, por exemplo, um limite máximo de $R \$ 2$ milhões para todas as perdas financeiras que tenham origem em seus riscos não-específicos e que tais perdas ocorram em não mais de cinco meses dentre os próximos cem (BANKS, 2002).

\footnotetext{
${ }^{4}$ Discussões sobre riscos empresariais já são bastante comuns nos Relatórios de Administração de empresas americanas e européias, mas são ainda muito raras entre as empresas brasileiras de capital aberto.
} 


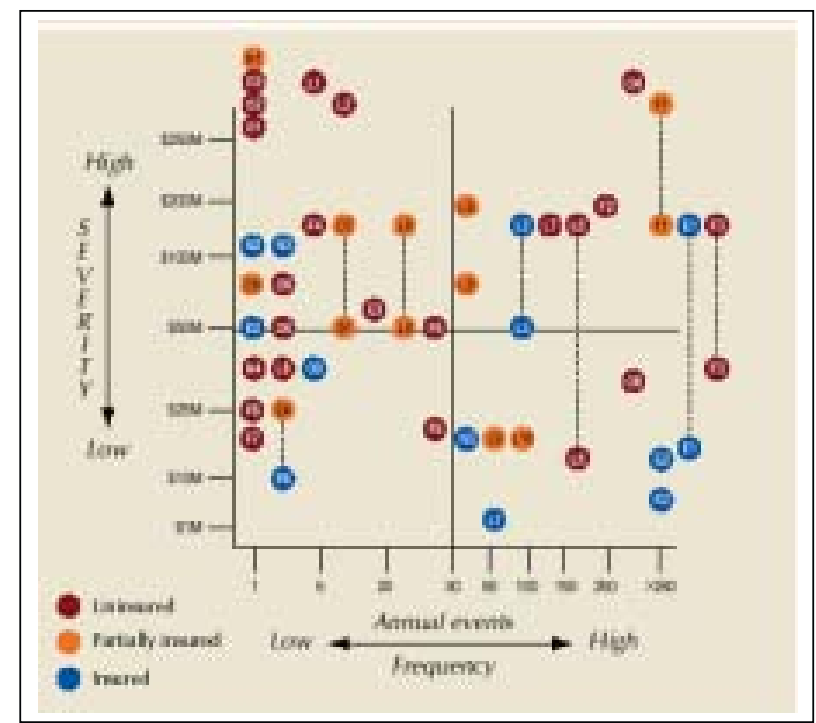

Quadro 1: Mapa Geral de Controle de Riscos

Como se chega a tais tolerâncias máximas? É sempre um exercício de julgamento, que depende da atitude perante o risco dos conselhos e de algumas considerações fundamentais. Uma empresa não pode, por exemplo, aceitar perdas de ativos ou resultados que possam levar à paralisação de suas atividades ou aceitar um abalo muito significativo dos resultados esperados pelos seus acionistas/proprietários. Assim, no caso de um risco com potencial destrutivo, as decisões sobre as limitações de perdas irão depender muito do montante das reservas de recursos existentes ou mobilizáveis na empresa e da particular atitude ou "apetite" da governança em relação ao risco. Determinados Conselhos acreditam, por exemplo, que os "riscos naturais do negócio", que são aqueles inerentes ao empreendimento (produção e vendas, por exemplo), devem ser suportados internamente sem limites. Outros Conselhos, por outro lado, jamais aceitariam tal risco ilimitado e cercariam a empresa de proteções contra os riscos de demandas contra produtos, contingências trabaIhistas, fraudes, etc. (SHIMPI, 2001).

É para cumprir as diretrizes e limites fixados pela governança que os gestores vão escolher as técnicas específicas de gestão de risco que serão colocadas em prática. Essas técnicas são as seguintes:
- Diversificação: distribuição do risco entre um número mais amplo de ativos de modo a reduzir o risco geral de perdas ou danos sobre eles.

- Imunização: formulação de atividades e controles para prevenir, detectar ou conter eventos adversos ou limitar as perdas ligadas a tais eventos.

- Compartilhamento: distribuição de uma parte do risco para outra pessoa física ou jurídica, como, por exemplo, através de uma terceirização.

- Neutralização: realização de determinadas operações financeiras, que, no evento de um "sinistro", geram resultados que possam compensar os prejuízos ocorridos.

- Transferência: distribuição de todo o risco para uma terceira pessoa através de um contrato, como, por exemplo, através de um seguro.

- Retenção: aceitação ativa e consciente de que as perdas ligadas a determinados riscos serão absorvidas total ou parcialmente pelo próprio patrimônio da empresa ${ }^{5}$.

Em geral, a governança atribui aos administradores o direito de decidir as técnicas específicas de gestão de risco que serão utilizadas na empresa, com a condição de que o patrimônio dos acionistas, em termos de perdas prováveis em suas exposições ao risco, permaneça dentro dos limites fixados. As únicas exceções a essa regra de ampla delegação dizem respeito aos chamados riscos extremos ou de alto impacto, mencionados acima. Como a ocorrência de alguns desses riscos pode levar à solução da continuidade da organização, a governança sempre determina limites estreitos para a sua retenção e aprova diretamente as técnicas de imunização e transferência propostos pela direção executiva para a sua gestão (especialmente os valores de cobertura dos seguros). A parte mais crucial do controle da custódia é a monitoria da gestão de riscos feita pelos administradores, pois, além da simples fiscalização do cumprimento dos limites e políticas fixados pela governança (compliance), deve verificar a própria adequação dos métodos utilizados para geri-los.

\footnotetext{
${ }^{5}$ Esta aceitação pode ser ativa ou passiva, consciente ou inconsciente. É claro que só se pode falar em gestão de risco se for ativa e consciente.
} 


\section{O CONTROLE DO DESEMPENHO EM RELAÇÃO AO RISCO E AO RETORNO}

Para o exercício da governança pelo Conselho, o controle do desempenho da empresa é absolutamente essencial. Nos estritos limites deste trabaIho não se pode apresentar toda a imensa discussão teórica e prática sobre as técnicas mais adequadas para medir o desempenho de uma empresa. Deve-se destacar, todavia, os princípios de controle que são fundamentais para uma governança eficaz (GEORGE, 1996):

- Para os acionistas/proprietários o retorno e o crescimento de seus investimentos são as bases de suas expectativas em relação à empresa.

- A produção de valor para os acionistas/proprietários está condicionada à produção simultânea de valor para os clientes/usuários e outros stakeholders da empresa.

- O risco é absolutamente inerente às atividades empresariais. Tanto a gestão como a governança empresarial precisam, pois, de informações antecipadas relativas aos fatores ambientais (de dentro e de fora da empresa), que podem representar ameaças ou oportunidades e, dessa forma, assegurar que a organização cumpra adequadamente os seus objetivos, harmonizando riscos e retornos (LAFUENTE, 2001).

- O controle do desempenho deve ter capacidade preditiva, estar focalizado nos fatores realmente causais dos resultados e, com isso, proporcionar o necessário fundamento às decisões e ações de determinação dos rumos empresariais e, quando necessário, sua correção.

- Os riscos de agenciamento sempre estão presentes, já que, como disseram Jensen \& Mekling (1999), "all business risks are also risks of poor management".
Para atender aos fundamentos acima, a formulação de um sistema de controle de desempenho em regime de risco para a governança envolve os seguintes elementos: (1) fixação da missão, dos objetivos e das metas gerais para os stakeholders, colocando o risco em evidência; (2) diagnóstico externo e interno dos riscos e dos fatores críticos do retorno e do risco; (3) realização de projeções financeiras, levando em consideração o possível impacto dos riscos; e, finalmente, (4) a organização de todos os dados (1), (2) e (3) de forma integrada, sistemática e coerente e sua comunicação sem qualquer viés para o conselho (SHIMPI, 2001).

Fixação da missão, dos objetivos e das metas da empresa.

É atribuição exclusiva da governança determinar o que a empresa é ou será, em termos do que deve produzir e para quem (missão) e qual o benefício que deverá efetivar com sua existência (objetivos e metas). Para que possa fazê-lo, ela deve partir da visão de seus participantes relevantes (stakeholders) polares ou primários, aqueles para os quais ela deve produzir valor ou, em outros termos, aqueles cujos interesses ela deve satisfazer de forma prioritária ${ }^{6} \mathrm{com}$ seus resultados, conforme a Figura 3.

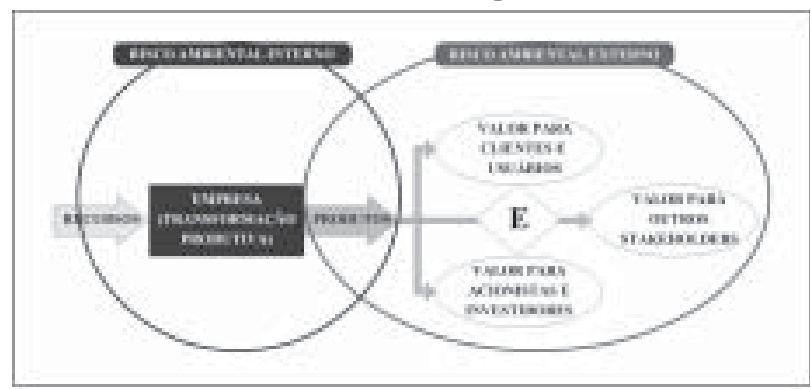

Figura 3: Produção de Valor nas Empresas em Regime de Risco

Cada participante relevante primário vai exigir da governança a formulação de um grupo de objetivos voltados para os seus interesses específicos, os

\footnotetext{
${ }^{6}$ Nos estudo acadêmicos sobre governança, há uma grande discussão a respeito das prioridades ou hierarquia que a empresa deveria conferir aos interesses dos diferentes participantes relevantes ou stakeholders. Os chamados generalistas, atribuem a todos os stakeholders igual importância, deixando à governança e aos executivos empresariais a obrigação nada fácil de buscar a conciliação desses interesses. O presente trabalho se filia a um grupo de autores mais conectados com a realidade social de nossa época, que atribui prioridade aos investidores / proprietários, por causa da característica residual de seus direitos aos resultados da empresa, isto é, somente podem considerar como disponíveis para si os resultados, após terem sido cumpridos todos os direitos legais dos demais stakeholders. Os clientes / usuários também aparecem como stakeholders primários somente porque sem eles, não haveria mercado para os produtos da empresa e, ipso facto, a empresa não teria existência. Os demais stakeholders devem ser legalmente atendidos e compensados, mas não mais do que isso. Todavia, sempre que numa dada situação ou num tipo particular de negócio a existência ou a competitividade da empresa tiver uma dependência orgânica e inevitável em relação a qualquer outro stakeholder (credores numa empresa em processo de concordata ou falência, por exemplo), este stakeholder também deve ser considerado primário ou polar.
} 
quais, no seu conjunto, se tornarão as dimensões do desempenho empresarial, ou seja, a mensuração do desempenho deve estabelecer um sistema de coleta e avaliação de informações, que permita aferir, através de diferentes instrumentos e métricas, a capacidade e o grau de eficiência e eficácia da produção do valor empresarial para os stakeholders primários selecionados. Como toda firma tem sempre pelo menos dois stakeholders primários, os seus clientes/usuários e os seus acionistas/investidores, a mensuração do valor que produz também deve ser feita sempre com pelo menos duas dimensões de desempenho (CARLSSON, 2001; CANO, 2002).

A formulação dos objetivos organizacionais por parte da governança deve ser feita de modo a permitir uma mensuração de desempenho inequívoca. Assim, para cada stakeholder primário os objetivos devem ser estipulados quantitativamente na forma de metas, com unidades de medida e formas de mensuração ${ }^{7}$ perfeitamente identificadas. Por exemplo, para os acionistas/proprietários não basta afirmar que a empresa deve produzir um retorno aos seus investimentos. Esse objetivo deve ser estipulado quantitativamente, em termos de um nível ou padrão mínimo a ser atingido, que é o custo do capital próprio (por exemplo: 20\% aa) e de um nível ou padrão relativo, que deve comparar a empresa com seus concorrentes (por exemplo: apresentar sempre um retorno acima da média das empresas do setor).

Entretanto, como a produção de valor para os stakeholders da empresa está sempre envolvida num ambiente de incertezas, a governança deve estipular, também, metas de risco de desempenho e custódia específicas para cada um deles. Por exemplo, para o caso dos investidores, além das metas financeiras usuais de retorno e crescimento patrimonial, deve, também, ser estipulada pela governança a sua tolerância máxima em relação às possíveis diferenças futuras entre as metas de resultados e a realidade (risco de desempenho), além da sua máxima tolerância em termos de perdas de ativos (risco de custódia). No caso dos clientes/usuários, para os quais a empresa deve ter metas de satisfação a serem cumpridas, a tolerância da governança pode ser expressa, por exemplo, através de um percentual mínimo dessa satisfação a ser atingido (risco de desempenho) e de uma perda máxima de clientes (risco de custódia).

Análise ambiental externa e interna

É nesta análise, em geral feita pela administração com o auxílio de consultores, que são identificados, na produção de valor, os riscos externos (na forma de ameaças, tais como a vulnerabilidade à taxa cambial, ameaça de ingresso de novos concorrentes, emergência de novas tecnologias, mudança de preferências e hábitos de compra dos consumidores ou oportunidades, tais como: a expansão de certos segmentos de mercados, novas preferências e hábitos de compra dos consumidores, etc.) ou internos (na forma de ameaças, tais como: problemas de qualidade dos produtos, processos de apoio altamente onerosos ou ineficientes, deficiências em relação a recursos importantes para obter competitividade ou na forma de oportunidades, tais como: o domínio da tecnologia dos processos, a motivação e produtividade do quadro de engenheiros, etc.).

O cumprimento dessa segunda etapa exige um vasto recolhimento de informações. Quais informações? Aquelas que seriam as mais relevantes para diagnosticar a situação atual da organização em relação ao seu desempenho perante os stakeholders primários e os concorrentes, assim como as que nos permitiriam conhecer, prever e avaliar os impactos dos riscos cruciais sobre os resultados empresariais futuros. Para Drucker (1989) essas informações são "as que se referem aos fatores críticos do ambiente externo e interno, pois são eles que diagnosticam e direcionam o futuro das empresas."

Os fatores críticos vitais para o controle de desempenho são identificados a partir de quatro questões fundamentais (GRANT,1991): (a) O que nossos clientes/usuários desejam? (b) O que a empresa precisa ter ou fazer para sobreviver e se desenvolver na arena competitiva? (c) Quais são os fatores externos, sistêmicos ou setoriais, que afetam (a) ou (b)? (d) Quais os processos e recursos internos que estão diretamente conectados com (a), (b) ou (c)?

Para responder à primeira questão, necessita-se uma visão tão próxima e detalhada dos clientes/usuários que permita reconhecê-los como a própria base

\footnotetext{
As medidas devem necessariamente conjugar as de natureza financeira (ao se tratar do retorno para os investidores), com as de natureza não-financeira (ao se tratar, por exemplo, da satisfação dos clientes/usuários).
} 
da existência dos negócios e seu comportamento de compra como a fonte primeira dos resultados para todo e qualquer stakeholder de uma empresa, a partir dos acionistas/proprietários. Isso significa que a empresa deve identificar as necessidades e interesses dos clientes/consumidores, segundo as quais eles selecionariam e dariam preferência à empresa sobre os demais fornecedores de produtos concorrentes. Facilmente se pode perceber tanto os riscos negativos (ameaças) como os positivos (oportunidades) envolvidos nessa questão: a empresa distingue e acompanha as tendências das preferências dos consumidores? Há um número suficiente de consumidores dispostos a dar preferência aos produtos da empresa? Há segmentos de mercado ainda não explorados?

Para responder à segunda questão, é necessário saber qual é a intensidade e quais são as dimensões básicas da competição na área de negócios da empresa? Se, por exemplo, no setor em que a empresa trabalha os produtos negociados são verdadeiras commodities indiferenciadas e se há poucas oportunidades para realizar uma diferenciação, seja através de qualificações específicas dos bens e serviços vendidos, seja através de uma atuação de mercado mais intensa de publicidade e/ou promoção, então o foco mais provável da concorrência é o preço. Para sobreviver e prosperar num setor em que a concorrência é baseada nos preços, a empresa deve buscar uma posição estratégica de baixos custos. A partir de informações setoriais de escala de produção, capacidade instalada aproveitada e ociosa, proporção de custos fixos sobre os custos totais, etc., a empresa pode articular tal estratégia de obtenção de vantagens competitivas de custos. Alguns riscos seriam: a empresa teria capacidade tecnológica para liderar pelos custos? Seus processos primários e de suporte estariam suficientemente enxutos de desperdícios? Sua automatização seria suficiente?

Para responder à terceira questão, necessita-se saber como os fatores sistêmicos, aqueles que são prevalecentes num país como um todo ou num determinado setor, tais como os políticos, os econômicos, os sócio-culturais, os tecnológicos, etc., podem influenciar os comportamentos de compra dos clientes/usuários ou as forças competitivas do setor. Oportunidades e ameaças ligadas a esse tópico são facilmente discerníveis. Por exemplo, a empresa resistiria a uma abertura do mercado de importação (retirada da proteção alfandegária) de seu principal produto? Qual seria o impacto sobre seus resultados e sua posição competitiva de um aumento súbito da taxa do dólar? Atuam dentro do seu setor forças "políticas" que poderiam levar a vantagens competitivas sobre a concorrência através, por exemplo, da obtenção de um empréstimo subsidiado?

Finalmente, em relação à quarta questão, a empresa precisa conhecer os fatores críticos internos, que são aqueles que, estando sob o domínio mais amplo da empresa, podem ser as bases de suas vantagens competitivas. Tais fatores devem ser buscados na análise competitiva de seus produtos, de sua atuação de mercado, de seus processos e recursos, de seus sistemas de trabalho, de sua estrutura organizacional, etc. Um dos pontos mais importantes desse tópico, cuja discussão excede os limites deste trabalho, diz respeito às imensas oportunidades (e ameaças) que estão associadas aos recursos intangíveis de base humana, entre os quais aparece com destaque a capacidade de gestão da equipe de administradores. Esse é provavelmente o mais importante recurso diretamente responsável pelo sucesso (e pelo fracasso) das empresas na busca de seus objetivos (JENSEN \& MECKLING, 1999).

\section{O desempenho projetado da empresa}

O modelo contábil-financeiro de uma empresa é um excelente instrumento para integrar e dar coerência à avaliação de desempenho. Avaliar os resultados financeiros futuros de uma empresa, a partir de um processo orçamentário estratégico-operacional, faz parte da contabilidade gerencial convencional e simulações de resultados com maior ou menor sofisticação constituem, hoje, uma ferramenta de uso comum nas Controladorias, mas, raramente, elas incluem, explicitamente, os riscos empresariais. Inserindo nessas projeções de retorno e crescimento os impactos previstos com a simulação dos riscos, temse um novo instrumento de controle, que é tão importante para a gestão como para a governança (PEARSON, 2002) ${ }^{8}$.

\footnotetext{
${ }^{8}$ Essa conjugação das previsões de resultados com a impactação de riscos são feitas hoje com alguma facilidade com o uso de softwares especializados, tais com o@Risk e o CrystalBall.
} 
Como exemplo, uma empresa brasileira de exportação de grãos e produção de óleos comestíveis faz cenários sobre a possível incidência de fatores de risco sobre seus resultados nos próximos 24 meses e faz da variação estimada desses resultados uma medida de risco. Outra, ligada à construção civil, já citada anteriormente, utiliza a sua experiência histórica de incidência dos fatores de risco sobre seu fluxo de caixa para realizar simulações de impactos pelo método bootstrapping, também dentro de um horizonte de planejamento de dois anos. Em relação a essa última empresa, vê-se na Figura 4 o resultado dessas simulações.

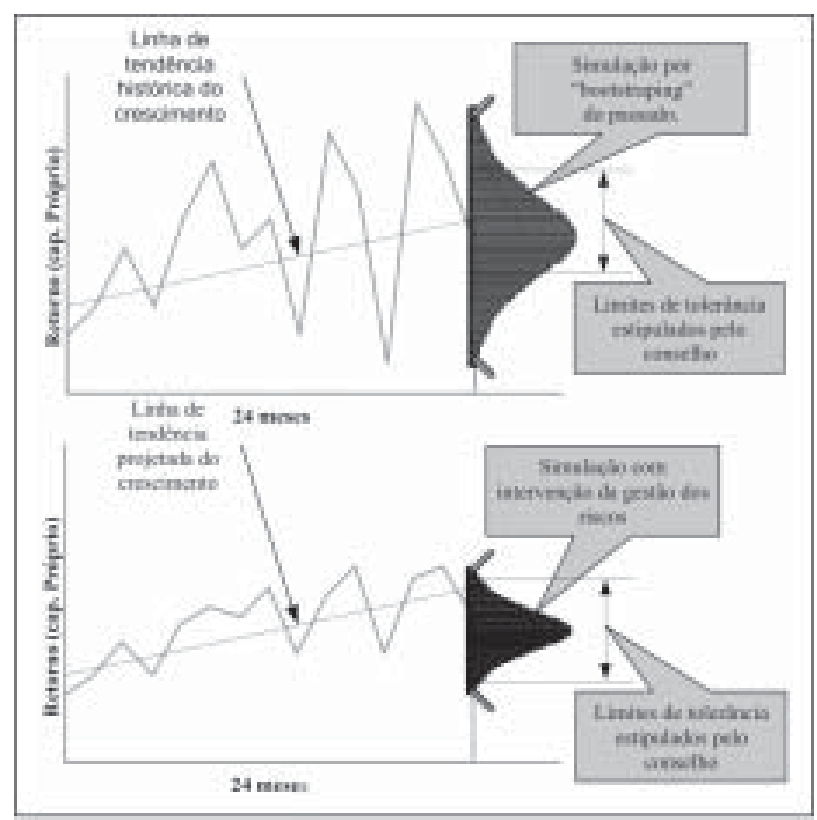

Figura 4: Simulações de risco-retorno

$\mathrm{Na}$ parte superior da figura, encontra-se o resultado da simulação dos resultados dos próximos 24 meses da empresa, em que se fazem incidir os impactos "históricos" de risco. Fica evidente a ampla variação prevista dos resultados, que excedem amplamente os limites de tolerância estipulados pela governança. Na parte inferior, fazendo intervir técnicas de administração de risco mais bem planejadas, os gestores pretendem conseguir a manutenção da tendência histórica de crescimento dos resultados, mas reduzindo drasticamente a amplitude de sua variação, o que atenderia aos limites estipulados a um nível de $90 \%$ de confiabilidade.

\section{CONTROLE DA QUALIDADE DA INFORMAÇÃO E O NOVO MODELO DE CONTROLADORIA}

Como deve ser implantado nas organizações o sistema de controle da gestão dos recursos para que o apoio à governança seja eficaz e eficiente? Qual seria o órgão mais adequado para manejar as técnicas e os instrumentos necessários às suas funções?

Poder-se-ia pensar num departamento especializado para a análise dos riscos, como é proposto por alguns autores, sob o nome EWRMD (Enterprise-Wide Risk Management Department) (DELOACH, 2000). Outros, por sua vez, acham que o ideal seria incluir as atribuições do controle da gestão dos recursos entre as do $\mathrm{ClO}$ (Chief Information Officer) (BOAR, 1994). Outros, afinal, propõem a Controladoria (BRITO, 2000). Merecem preferência esses últimos, uma vez que o risco é inerente às atividades empresariais e é impossível perseguir resultados econômicos sem incorrer em riscos. Como foi visto acima, o modelo contábil-financeiro das empresas, se acompanhado de algumas extensões e adições, é particularmente moldado para analisar, acompanhar e projetar a aplicação dos recursos nas empresas e o seu desempenho em regime de risco, conforme é do interesse da governança. Logo, os controles de desempenho e custódia, que sempre empregaram a Contabilidade Financeira e Gerencial, devem ser realizados dentro da organização de forma unificada e coerente com o controle de riscos, sem o que não se poderia, realmente, preparar um quadro global de controle empresarial com critérios consistentes e, o que é mais importante, verificar se os gestores estão fazendo a harmonização dos riscos e retornos de forma apropriada (ALLEN \& GALE, 2000).

Mas há um problema: o da independência. Lembrando, mais uma vez, a frase acima citada de Jensen \& Meckling (1999), uma Controladoria, ao fazer o controle do risco/retorno dos recursos empregados na empresa, inevitavelmente estaria fazendo, também, uma auditoria da gestão dos administradores encarregados de tomar decisões sobre tais recursos. Todavia, um Controller, ainda que fosse um diretor, ficaria numa posição insustentável perante um Presidente, caso se subordinasse a ele e tivesse que criticá-lo perante o Conselho. Por outro lado, se não o fizesse e deixasse que as informações de seus relatórios fossem 
"filtradas" ou "depuradas" das análises negativas sobre a atuação e as capacidades dos administradores, todo o sistema de controle poderia ser posto a perder pela ação do agenciamento (GUEDJE \& KÜBLER, 2000). Isso é o que, na verdade, ocorre, atualmente, na maioria das empresas. Entretanto, com tais restrições fica limitado o papel das Controladorias - e, consequentemente, o da governança - para prevenir e evitar crises e garantir a continuidade empresarial.

Assim, uma nova posição organizacional das Controladorias é absolutamente necessária para que haja o exercício efetivo da governança. Esse novo modelo desvincula hierarquicamente a Controladoria da gestão e estabelece uma dupla ligação estrutural. De um lado, a ligação do Controller com os principais executivos da empresa seria puramente informacional: eles sempre teriam o direito de receber todas as informações geradas pelo sistema de controle de custódia e do desempenho. Do outro lado, o Controller ficaria subordinado diretamente ao Conselho de Administração (CANO, 2002). Nessas condições, um Presidente nunca poderia demitir um Controller sem prévio assentimento do board, da mesma forma que o executivo responsável por uma unidade de negócios também não poderia demitir um Divisional Controller sem prévia concordância do Controller Geral do grupo empresarial.

Dessa forma, com sua posição e sua carreira a salvo, os Controllers poderiam garantir sistemas de controles da gestão dos recursos, cuja veracidade e qualidade informativa seriam totalmente isentos da possível contaminação pelo agenciamento, o que nenhum órgão da estrutura organizacional que seja subordinado à direção executiva jamais poderia assegurar. Diga-se de passagem que essa posição de independência não é nova e, por motivos que nessa altura devem estar claros, já é hoje estendida aos auditores internos (CANO, 2002) ${ }^{9}$.

\section{CONCLUSÕES}

Na maior parte das discussões sobre o papel da governança, muito pouco foi escrito até o momento sobre a necessidade de que o Conselho de Administração garanta a existência e o correto funcionamento dentro da empresa de um sistema de controles internos para que suas atribuições legais possam ser desempenhadas de acordo com as expectativas dos acionistas/proprietários, cujos interesses eles representam.

Neste trabalho foi demonstrado que a tarefa básica da governança é garantir que os recursos empresariais sejam empregados de forma eficiente e eficaz na missão, objetivos e metas da organização. Entretanto, como os que têm o dever e o poder de governança não são os que dirigem e tomam decisões sobre os recursos, há uma inexorável necessidade de que haja, internamente, um sistema de controles especialmente voltados para o controle da custódia e do desempenho. Sem tal sistema não poderia haver uma governança efetiva. A possibilidade da existência de uma governança empresarial deve ser equacionada definitivamente como um problema de controles internos, além, é claro, da disposição dos Conselhos para exercê-la. A existência dos riscos empresariais, todavia, torna tais controles mais complexos, exigindo o que foi, aqui, chamado de sistema de controle de risco/retorno, cujas características gerais foram delineadas.

Como os riscos de agenciamento estão sempre presentes nas empresas em que há a separação entre a propriedade e a gestão, foi comentada a necessidade de que o sistema de controle tenha uma estrutura organizacional de forma unificada nas Controladorias, as quais deveriam ser totalmente independentes hierarquicamente do sistema de administração. A unificação dos controles é vital porque cada processo, cada função, cada executivo de uma empresa deve ser objeto de controles de desempenho e de custódia, que, se devem ser atomizados para focalizar cada um deles, devem também, mais que tudo, ser objeto de uma síntese, pois cada parte de uma organização não deve ser analisada isoladamente, pois sua existência só tem sentido se estiver contribuindo para um todo. Só uma Controladoria poderia exercer tais controles internos de forma a sintetizá-los dentro do modelo contábil-financeiro de avaliação empresarial. A separação hierárquica da gestão executiva da organização, por seu lado, é óbvia quando atentamos que os controles internos não podem ficar subordinados a quem poderá estar

${ }^{9}$ No novo modelo os auditores internos ficariam integrados à Controladoria. 
sendo objeto desses controles. Como seria exercido o controle da qualidade e da veracidade das informações?

Alguns poderão objetar dizendo que os controles também servem à gestão empresarial, já que os administradores precisam deles para avaliar o seu próprio desempenho e o efeito das decisões que tomam no comando empresarial em regime de risco. Isto também é óbvio. $O$ conhecimento, a identificação e a gestão dos riscos empresariais fazem parte da própria essência da administração moderna. Mas isto não implica que o sistema de avaliação da gestão desses riscos, que deve ser feito pelas Controladorias, deva se subordinar à gestão. Só a independência dessa avaliação garante a independência dos controles, os quais, por sua vez, constituem a própria essência e a validade de uma governança.

As deficiências de governança, que já levaram tantas empresas a situações de crise e falêneia colapso, como as que foram citados na abertura deste trabalho, encontram-se exatamente na incapacidade ou na falta de disposição dos Conselhos de instalar e manter um sistema de controles internos competente e independente (VIVES, 2000; JENSEN \& MECKLING, 1999). O novo modelo proposto de Controladoria é a resposta.

\section{REFERÊNCIAS BIBLIOGRÁFICAS}

ALLEN, F. \& GALE, D. Corporate Governance and Competition, in Corporate Governance, Vives: Cambridge University Press, 2000.

BANKS, E. The Simple Rules of Risk, John Wiley \& Sons, 2002.

BARTON, T. L. et al. Making Enterprise Risk Management Pay Off, Prentice Hall, 2002.

BRITO, O. S. Contribuição ao Estudo de Modelo de Controladoria de Risco-Retorno em Bancos de Atacado. 2000. Tese (Doutorado em Controladoria e Contabilidade) Faculdade de Economia, Administração e Contabilidade, Universidade de São Paulo, USP.

CANO, N. M. Da Contabilidade à Controladoria: a Evolução Necessária. Revista de Contabilidade e Finanças da USP, São Paulo, Ano XIII, N. 28, p. 7-28, jan/abr. 2002.

CARLSSON, R. H. Ownership and Value Creation, John Wiley \& Sons, 2001.

CROUHY, M. et al. Risk Management, McGraw Hill, 2001.

CULP, C. L. The Art of Risk Management, John Wiley \& Sons, 2002.

DELOACH, J. W. Enterprise-Wide Risk Management - Strategies for Linking Risk and Opportunity, Financial Times \& PrenticeHall, 2000.

DOHERTY, N. A. Integrated Risk Management, McGraw Hill, 2000.

DRUCKER, P. As Novas Realidades, Pioneira, 1989.
GEORGE, A. M. Protecting Shareholder Value, Irwin, 1996.

GLEASON, J. T. Risk: The New Management Imperative in Finance; Bloomberg Press, 2000.

GRANT, R. M. Contemporary Strategy Analysis, Basil Blackwell, 1991.

GUEDJE, N. \& KÜBLER, F. Le Management de l'information: Comme Utiliser Vôtre Contrôle de Gestion, in Le Contrôle de Gestion (GUEDJE, N. Coordinateur), Éditions d'Organisation, $3^{\text {éme }}$ Ed., 2000.

HARRIS, M. \& TOWNSEND, R. M. Resource Allocation Under Assymetric Information, Econometrica, p. 33/64, January, 1981.

HART, O. Firms, Contracts and Financial Structure, Oxford Clarendon Press, 1995.

HELLWIG, M. On the Economics and Politics of Corporate Finance and Corporate Control, in Corporate Governance, Ed. Vives, X., Cambridge University Press, 2000.

JENSEN, M. C. \& MECKLING, W. H. Coordination, Control and the Management of Organizations, Harvard Business School Working, Paper \#98-098, 1999.

MACCRIMMON, K. R. \& WEHRUNG, D. A. Taking Risks, The Free Press, 1986.

MALHOTRA, N. K. Marketing Research, Prentice Hall, $3^{\text {rd }}$ Ed., 1999.

MARCH, J. G. \& SHAPIRA, Z. Managerial Perspectives on Risk and Risk Taking, Management Science, V. 33, No. 11, November, 1987. Times Prentiisk Budgeting, John Wiley \& Sons, 2002. 
PRATT, J. W. \& ZECKAUSER, R. J. Principal and Agents: the Structure of Business, Harvard Business School Press, 1984.

RAJAN, R. \& ZINGALES, L. The Governance of the New Enterprise, in Corporate Gover-nance, Ed. Vives, X., Cambridge University Press, 2000.

LAFUENTE, A. M. G. Nuevas Estrategias para el Analisis Financiero, Editorial Ariel, 2001.
SHIMPI, P. A. Integrating Corporate Risk Management, Texere, 2001.

TEDLOW, R. S. \& JOHN JR, R. R. Managing Big Business, Harvard Business School Press, 1986.

Vives, X. Corporate Governance: Does It Matter?, in Corporate Governance, Ed. Vives, X., Cambridge University Press, 2000.

YOUNG, P. C. \& TIPPINS, S. C. Managing Business Risk, AMACON, 2001.

\section{BIBLIOGRAFIA COMPLEMENTAR}

Basle Committee, Internal Control Systems in Banking Organizations, Basle, 1998.

BAVLY, D. A. Corporate Governance and Accountability, Quorum Books, 1999.

BESSIS, J. Risk Management in Banking, John Wiley \& Sons, 2002.
Board, B.H. Aligning Information Technologies with Business Strategies, John Wiley \& Sons, 1994.

JORION, P. Value at Risk, McGraw Hill, $2^{\text {nd }}$ Ed, 2001.

\section{NOTA:}

Endereço dos autores:

NILTON CANO MARTIN

Av. Prof. Luciano Gualberto, 908

Cidade Universitária - Butantã

São Paulo - SP

05508-900

LÍLIAN REGINA DOS SANTOS

Praça Alfredo Egídio de Souza Aranha, 100

Jabaguara

São Paulo - SP

04344-902

JOSÉ MARIA DIAS FILHO

Km 3, BR 116 - Campus Universitário

Feira de Santana - BA

44.031-460 